\title{
Plasma profiles of adrenocorticotropic hormone, cortisol, a-melanocyte-stimulating hormone, and growth hormone in dogs with pituitary-dependent hyperadrenocorticism before and after hypophysectomy
}

\author{
J M Hanson, H S Kooistra, J A Mol, E Teske and B P Meij \\ Department of Clinical Sciences of Companion Animals, Faculty of Veterinary Medicine, Utrecht University, Yalelaan 8, PO Box 80.154, NL-3508 TD Utrecht, \\ The Netherlands \\ (Requests for offprints should be addressed to J M Hanson; Email: j.m.hanson@vet.uu.nl)
}

\begin{abstract}
The 6-h plasma profiles of adrenocorticotropic hormone $($ ACTH), cortisol, $\alpha$-melanocyte-stimulating hormone $(\boldsymbol{\alpha}-\mathrm{MSH})$, and GH were studied in 17 dogs with pituitarydependent hyperadrenocorticism (PDH) before and after hypophysectomy. The aim of the study was to investigate the relation between the hormone profile characteristics and recurrence of PDH after surgery.

The hormones were secreted in a pulsatile fashion. The basal plasma cortisol concentration and area under the curve (AUC) for cortisol were significantly higher in the PDH cases than in eight controls. The characteristics of the plasma profiles of ACTH and $\alpha$-MSH were not significantly different between the PDH cases and the controls. In the PDH cases, less GH was secreted in pulses than in the controls, but the difference was not significant. The basal plasma cortisol concentration, the AUC for ACTH and cortisol, and the pulse frequency of ACTH and cortisol decreased significantly
\end{abstract}

after hypophysectomy for the group of PDH cases. The basal plasma concentrations of ACTH and $\alpha-\mathrm{MSH}$, the AUC for $\alpha$-MSH, and the characteristics of the plasma GH profiles of the PDH cases remained unchanged after hypophysectomy. No pulses of $\alpha$-MSH were observed after hypophysectomy. The co-occurrence between the ACTH and cortisol pulses decreased significantly with hypophysectomy. The postoperative pulse frequency of ACTH was the only characteristic with predictive value for the recurrence of PDH after hypophysectomy.

The results of this study demonstrate that ACTH, cortisol, $\alpha-\mathrm{MSH}$, and GH are secreted in a pulsatile fashion in dogs with PDH. Hypophysectomy effectively reduces the secretion of ACTH and cortisol. The presence of ACTH pulses after hypophysectomy is a risk factor for the recurrence of hyperadrenocorticism.

Journal of Endocrinology (2006) 190, 601-609

\section{Introduction}

Pituitary-dependent hyperadrenocorticism (PDH) is a common spontaneous endocrine disorder in dogs, which shows many similarities with Cushing's disease in humans (Kemppainen \& Peterson 1994). As in humans with Cushing's disease (Lamberts 2002, Reimondo et al. 2003), PDH in dogs is characterized by adrenocorticotropic hormone (ACTH)induced hypercortisolism and reduced sensitivity to glucocorticoid feedback inhibition (Rijnberk et al. 1988a, Bosje et al. 2002), in most cases with preserved ability to respond to corticotrophin-releasing hormone (CRH) stimulation (Meij et al. 1997b, Reimondo et al. 2003). The excessive pituitary secretion of ACTH originates from a corticotropic adenoma in the pars distalis or the pars intermedia of the adenohypophysis. PDH caused by an adenoma in pars intermedia is often characterized by highly elevated plasma concentrations of $\alpha$-melanocyte-stimulating hormone $(\alpha-\mathrm{MSH})$ and strong resistance to dexamethasone suppression (Peterson et al. 1986, Rijnberk et al. 1988b, Bosje et al. 2002). In Cushing's disease, there are not only alterations in ACTH secretions but also in the secretion of other pituitary hormones (van den Berg et al. 1997, Roelfsema et al. 1998, Veldman et al. 2000). In dogs with PDH, these changes may include basal levels, response to stimulation (Meij et al. 1997b), as well as the pulsatile release pattern that is characteristic of pituitary hormone secretion (Kemppainen \& Sartin 1984, Brabant et al. 1992, Kooistra et al. 1997a, 1999, Kooistra \& Okkens 2001, Corrada et al. 2003, Lee et al. 2003). For example, plasma growth hormone $(\mathrm{GH})$ concentration and its responsiveness to stimulation with GH-releasing hormone (GHRH) have been reported to be decreased in dogs with PDH, most likely due to glucocorticoid-induced alterations in the function of pituitary somatotropic cells and changes in suprapituitary regulation (Meij et al. 1997b). In addition, canine PDH is associated with less GH secreted in pulses than in controls (Lee et al. 2003). 
Pituitary surgery is the treatment of choice in humans with Cushing's disease (Rees et al. 2002). Preferably, an adenomectomy is performed, but $15-26 \%$ of the cases undergo a total hypophysectomy (Barker et al. 2003). Transsphenoidal hypophysectomy is an effective treatment in dogs with $\mathrm{PDH}$ (Meij et al. 1998). In both species, recurrence of the disease is a serious problem. In a study on 150 dogs with PDH, the fraction that relapsed within 2 years after hypophysectomy was $25 \%$ (Hanson et al. 2005). In humans, the recurrence rate is $5-30 \%$ after pituitary surgery for corticotropic adenomas (Rees et al. 2002, Pereira et al. 2003).

After transsphenoidal hypophysectomy in healthy dogs, residual pituitary cells have been observed in the pituitary fossa (Niebauer et al. 1990, Meij et al. 1997d, Axlund et al. 2005). Such cells are devoid of the direct influence of the hypothalamus due to section of the pituitary stalk. Upon administration of secretagogs, the residual corticotropic cells appeared functional. They secreted ACTH after stimulation with CRH (Meij et al. 1997a). Stimulation with other secretagogs, e.g. thyroptropin-releasing hormone (TRH), GHRH, and gonadotropin-releasing hormone (GnRH), evoked no adenohypophyseal hormone secretion (Meij et al. 1997d). Eight weeks after surgery, the CRH stimulation test was not able to identify the dogs that would later relapse (Meij et al. 1997a). The pulsatile secretion pattern of remnant pituitary cells has not yet been studied. It was hypothesized that the secretion pattern would differ between remnant adenomatous and normal corticotropic cells and that the profile characteristics after hypophysectomy would hold predictive value for recurrence of hyperadrenocorticism.

Here, we report on the 6-h plasma profiles of ACTH, cortisol, $\alpha-\mathrm{MSH}$, and GH in dogs with PDH before and after transsphenoidal hypophysectomy. The aim of the study was to investigate the relation between the hormone profile characteristics and recurrence of PDH after surgery.

\section{Materials and Methods}

\section{Animals, diagnosis, and treatment of PDH}

Seventeen dogs of different breeds with PDH were included in the study. The group comprised two Miniature Poodles, one Dachshund, one Basset Fauve de Bretagne, one Cairn Terrier, one English Cocker Spaniel, one Pitt Bullterrier, one Shetland Sheepdog, one Soft Coated Wheaten Terrier, one Standard Poodle, one Welsh Corgi and six cross-bred dogs. There were 6 females ( 2 spayed) and 11 males ( 2 castrated) with a median age of 8 years (range 5-12 years), and a median body weight of $15 \mathrm{~kg}$ (range $7-27 \mathrm{~kg}$ ).

The diagnosis of hyperadrenocorticism was based upon averaged urinary corticoid-to-creatinine ratios (UCCR) in two consecutive morning urine samples. In all animals, the UCCRs (median, $44 \times 10^{-6}$; range, $23-321 \times 10^{-6}$ ) exceeded the ratios found in 87 healthy companion dogs (range $0 \cdot 3-8 \cdot 3 \times 10^{-6}$; van Vonderen et al. 1997). After collection of the second urine sample, three oral doses of $0.1 \mathrm{mg}$ dexamethasone per kilogram body weight were administered at intervals of $8 \mathrm{~h}$. In 13 cases, the UCCR in the third sample was less than $50 \%$ of the mean of the first two samples and PDH was diagnosed (Galac et al. 1997). In four cases, with less than 50\% suppression of the third UCCR, pituitary dependency was secured by measurements of plasma ACTH concentrations and further supported by visualization of the adrenals by ultrasonography and by pituitary imaging with computed tomography (CT; Rijnberk et al. 1987, Bosje et al. 2002, van der Vlugt-Meijer et al. 2002, 2003).

Transsphenoidal hypophysectomy was performed according to a microsurgical technique described previously (Meij et al. 1997c). Postoperative care and hormone supplementation were according to previously published protocols (Meij et al. 1997c, 1998, Hanson et al. 2005). Briefly, hydrocortisone and desmopressin were directly administrated after the removal of the pituitary gland. When the dogs had resumed drinking and eating, oral substitution therapy was started with cortisone acetate and thyroxin. The dose of cortisone acetate was gradually lowered over a period of 4 weeks to a physiological dose. Desmopressin was administered for 2 weeks routinely and continued if polyuria due to central diabetes insipidus persisted.

Re-examination after 8 weeks included physical examination, routine blood chemistry, measurements of basal plasma thyroxine concentration at 10-12 h after L-thyroxine medication, and basal UCCR in duplicate at $24 \mathrm{~h}$ after cortisone medication (median $1 \cdot 7 \times 10^{-6}$; range $0 \cdot 3-5 \cdot 2 \times$ $\left.10^{-6}\right)$. UCCRs were measured again half a year after surgery and thereafter once a year. In case of suspicion of recurrence, UCCRs were determined earlier. Urine samples were mailed to our laboratory and follow-up reports were obtained from the above-mentioned routine follow-up examinations in the hospital and during telephone conversations with the owner and/or the referring veterinarian.

There was one case of early postoperative mortality (within 4 weeks) due to kidney failure. In all 16 remaining dogs, there was remission: UCCR $<10 \times 10^{-6}$ and resolution of clinical signs of hyperadrenocorticism. Recurrence was defined as UCCR $\geq 10 \times 10^{-6}$ and/or return of signs and symptoms of hyperadrenocorticism after initial complete remission. This occurred in 9 out of the 16 cases after median 652 days (range 201-1679 days).

\section{Control dogs for pulsatile secretion}

The plasma profiles of cortisol, ACTH, and $\alpha-\mathrm{MSH}$ of the $\mathrm{PDH}$ cases were compared with those obtained in eight healthy beagle dogs (four intact females and four intact males, with body weight ranging from 12 to $25 \mathrm{~kg}$, and age ranging from 2 to 5 years; Kooistra et al. 1997a). The plasma GH profiles of the PDH cases were compared with those of plasma obtained from six healthy female beagle dogs (with body weight ranging from 12 to $27 \mathrm{~kg}$, and age ranging from 7 to 9 years; Lee et al. 2003). 
Sample collection for pulsatile plasma profile

In the $\mathrm{PDH}$ dogs, the $6-\mathrm{h}$ plasma hormone profiles were determined 2-34 days (median, 8 days) before surgery and 50-133 days (median, 71 days) after hypophysectomy. Preoperative 6-h plasma profiles of ACTH and cortisol were available from 17 cases, $\boldsymbol{\alpha}$-MSH from 14 cases, and $\mathrm{GH}$ from 14 cases. After hypophysectomy, 6-h plasma profiles of ACTH and cortisol became available from 14 cases, $\alpha-\mathrm{MSH}$ from 13 cases, and $\mathrm{GH}$ from 11 cases.

Food, but not water, was withheld from the animals $12 \mathrm{~h}$ prior to blood sampling. Blood samples $(4 \mathrm{ml})$ were collected from the jugular vein by an experienced technician at 10-min intervals between 0800 and $1400 \mathrm{~h}$. Blood was collected in pre-chilled EDTA-coated tubes on ice and centrifuged at $4{ }^{\circ} \mathrm{C}$ (2000 g, $\left.10 \mathrm{~min}\right)$. Plasma was stored at $-20^{\circ} \mathrm{C}$ until assayed.

This study on the pulsatile secretion was approved by the Ethical Committee of Utrecht University and for the PDH dogs informed consent was obtained from the owners.

\section{Hormone determinations}

Plasma ACTH concentration was measured using a commercially available two-site immunoradiometreic assay (IRMA; Nichols Institute, Wijchen, The Netherlands). The antiserum was highly specific for ACTH (1-39). A polyclonal antibody was bound specifically to the C-terminal region of ACTH. The radioiodinated monoclonal antibody was bound only to the N-terminal region of ACTH. The intra-assay coefficient of variation $(\mathrm{CV})$ was $3 \cdot 2 \%$, the inter-assay $\mathrm{CV}$ was $7 \cdot 8 \%$, and the sensitivity was $0 \cdot 22 \mathrm{pmol} / 1$. There was no crossreaction between the antiserum and $\alpha-\mathrm{MSH}$ or $\mathrm{ACTH}$ precursors (Raff \& Findling 1989, Bosje et al. 2002).

Plasma cortisol concentration was measured with a solid phase ${ }^{125}$ I RIA; Coat-A-Count Cortisol, Diagnostic Products Corporation, Los Angeles, CA, USA. The antiserum was highly specific for cortisol, with very low cross-reactivity to other compounds that were present in patient samples. Proteins, bilirubin, lipemia, and hemolysis had no significant effect on the assay. The intra-assay CV was $4 \cdot 5-6 \cdot 3 \%$, the inter-assay $\mathrm{CV}, 4 \%$, and the sensitivity, $5 \cdot 5 \mathrm{nmol} / 1$.

The urinary corticoid concentration was measured with RIA as described previously (Rijnberk et al. 1988a). The intra-assay $\mathrm{CV}$ was $6 \%$, the inter-assay $\mathrm{CV}, 8 \%$, and the sensitivity, $1 \mathrm{nmol} / \mathrm{l}$. The urinary corticoid concentration was related to the urinary creatinine concentration (Jaffé kinetic method, initial rate reaction) and the UCCR calculated (Stolp et al. 1983, Rijnberk et al. 1988a).

Plasma concentration of $\alpha-\mathrm{MSH}$ was measured with RIA without extraction as described previously (Rijnberk et al. 1988b). The intra-assay CV was 10\%, the inter-assay CV, 23\%, and the sensitivity, $3 \mathrm{pmol} / \mathrm{l}$. The antiserum had less than $0 \cdot 1 \%$ cross-reactivity with ACTH (1-39) and $4 \%$ crossreactivity with ACTH (1-24).
Plasma GH concentration was measured by a homologous RIA as described previously (Eigenmann \& Eigenmann 1981). The intra-assay $\mathrm{CV}$ was $3 \cdot 8 \%$, the inter-assay $\mathrm{CV}$, $7 \cdot 2 \%$, and the sensitivity, $0 \cdot 3 \mu \mathrm{g} / \mathrm{l}$. The degree of crossreaction of canine prolactin was $2 \%$.

\section{Statistical analysis}

The 6-h plasma hormone profiles were analyzed using the Pulsar program developed by Merriam \& Wachter (1982). The program identifies secretory peaks by height and duration from a smoothed baseline, using the assay S.D. as a scale factor. The cut-off parameters G1-G5 of the Pulsar program were set at $3 \cdot 98,2 \cdot 4,1 \cdot 68,1 \cdot 24$, and $0 \cdot 93$ times the assay S.D. as criteria for accepting peaks $1,2,3,4$, and 5 points wide. The smoothing time, a window used to calculate a running mean value, was set at $5 \mathrm{~h}$. The weight assigned to peaks was $0 \cdot 05$. The $A, B$, and $C$ values of the Pulsar program used to calculate the variance of the assay was set at $A=0, B=7 \cdot 1$, and $C=32$ for ACTH; $A=0, B=4 \cdot 8$, and $C=114$ for cortisol; $A=0, B=-2 \cdot 44$, and $C=451$ for $\alpha$-MSH; and $A=0, B=7 \cdot 2$, and $C=5$ for $\mathrm{GH}$. The values extracted from the Pulsar analyses included the overall mean of the smoothed baseline, area under the curve (AUC) above the zero level, and the number of significant pulses per $6 \mathrm{~h}$.

The differences in variables between control dogs and dogs with PDH were assessed by the non-parametric MannWhitney test (with Bonferroni correction). The differences in variables before and after surgery were assessed by Wilcoxonsigned ranks test for related samples (with Bonferroni correction). A $P<0 \cdot 05$ was considered significant. Fishers's exact test was used to analyze the co-occurrence of significant ACTH, cortisol, and $\boldsymbol{\alpha}-\mathrm{MSH}$ pulses.

Univariate Cox proportional hazard fit analyses were performed using Newton-Raphson algorithm for the disease-free period on the characteristics of the plasma hormone profiles (mean of the smoothed baseline, AUC, pulse frequency) for ACTH, cortisol, $\alpha-\mathrm{MSH}$, and $\mathrm{GH}$ before and after hypophysectomy.

\section{Results}

All four hormones were secreted in a pulsatile fashion in control dogs as well as in dogs with PDH (Fig. 1a and b). Representative graphs of the plasma profiles for the controls have been published previously (Kooistra et al. 1997a, Lee et al. 2003).

\section{ACTH and cortisol}

In the dogs with $\mathrm{PDH}$, the basal plasma cortisol concentration $(P<0 \cdot 005)$ and the AUC for cortisol $(P<0 \cdot 001)$ were significantly higher than those in the controls. There was no significant difference in the cortisol pulse frequency. After hypophysectomy, the basal plasma 


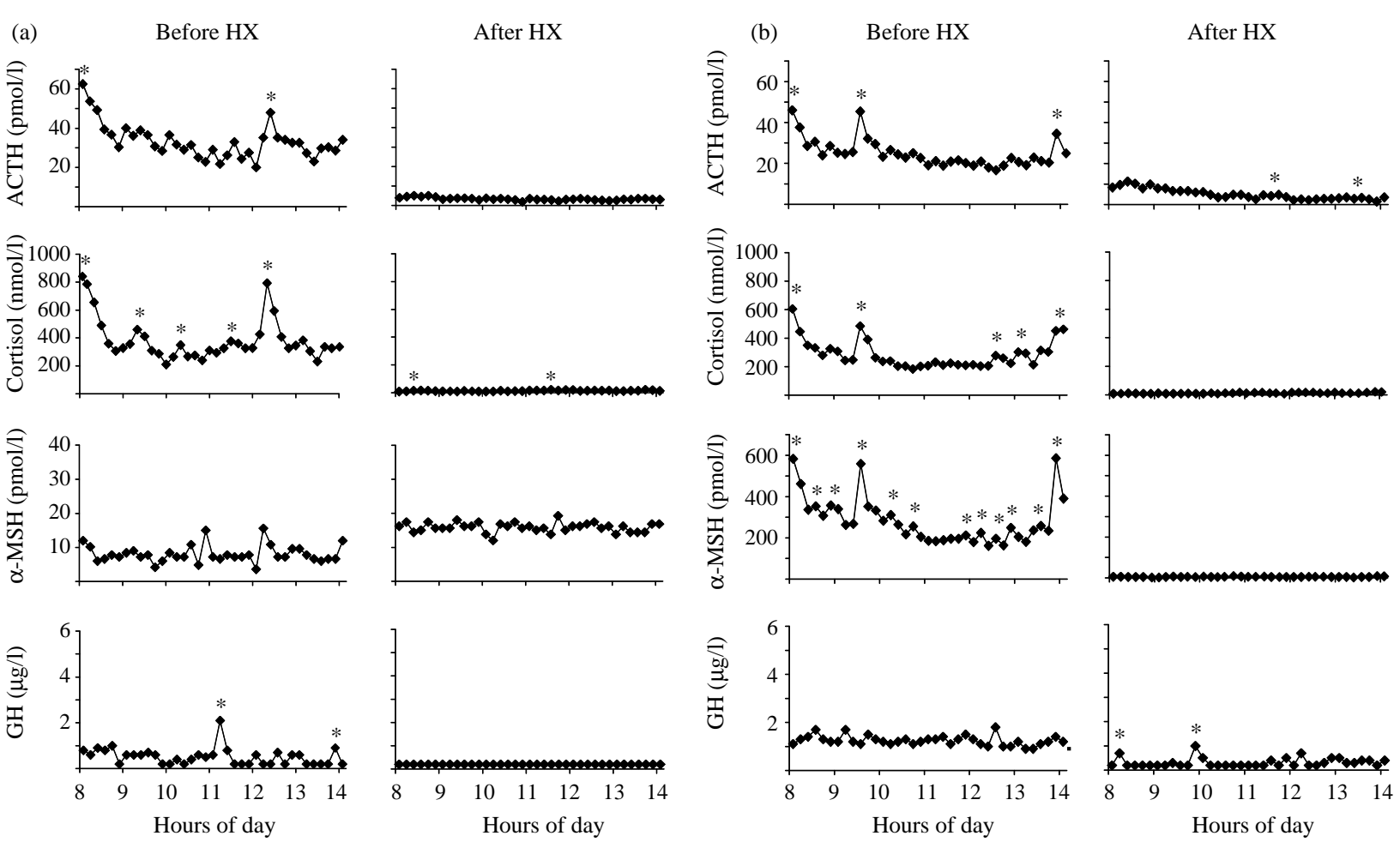

Figure 1 The plasma profiles of $\mathrm{ACTH}$, cortisol, $\alpha-\mathrm{MSH}$, and $\mathrm{GH}$ before and after hypophysectomy (HX) in (a) a representative dog with pituitary-dependent hyperadrenocorticism (PDH), and (b) a dog with PDH with markedly elevated plasma $\alpha$-MSH concentrations before hypophysectomy (note the difference in scale of the $y$-axis $1 \mathrm{~b}$ ). Blood samples were collected at 10-min intervals for $6 \mathrm{~h}$. *Peaks identified by the Pulsar programme.

cortisol concentration $(P<0 \cdot 005)$, the AUC for cortisol $(P<0 \cdot 005)$, and the cortisol pulse frequency $(P<0 \cdot 005)$ decreased significantly (Fig. 2). The basal plasma ACTH concentration, the AUC for ACTH, and the ACTH pulse frequency in the PDH dogs were not significantly different from those in the controls. Significant ACTH pulses were identified by the Pulsar program in 14 out of the 17 dogs with PDH. After surgery, the AUC for ACTH $(P<0 \cdot 05)$ and the ACTH pulse frequency $(P<0 \cdot 05)$ decreased significantly, whereas the basal plasma ACTH concentration tended to decrease $(P=0 \cdot 052)$ (Fig. 2). Significant ACTH pulses were identified in 10 out of the 14 cases after hypophysectomy; 8 of these 10 dogs had a recurrence later. Significant ACTH pulses were absent in 4 out of the 14 cases and 3 of these 4 dogs remained in remission.

In the PDH dogs and in the controls, the majority of ACTH pulses coincided with cortisol pulses. In the controls, 23 out of 26 significant ACTH pulses identified by the Pulsar program coincided with 21 out of 38 significant cortisol pulses. In the PDH cases, 32 out of 36 significant ACTH pulses coincided with 32 out of 65 significant cortisol pulses. The difference between co-occurrence of ACTH and cortisol pulses in control and PDH cases was not significant. After surgery, 5 out of 12 significant ACTH pulses coincided with 5 out of 26 significant cortisol pulses. The difference between co-occurrence of ACTH and cortisol pulses before and after surgery was significant $(P<0 \cdot 01)$.

\section{$\alpha-M S H$}

The basal plasma $\alpha$-MSH concentration, the AUC for $\alpha-\mathrm{MSH}$, and the $\alpha-\mathrm{MSH}$ pulse frequency in the PDH cases were similar to those in the controls. Significant $\alpha-\mathrm{MSH}$ pulses were identified in 7 out of the $14 \mathrm{PDH}$ cases. After hypophysectomy, no significant $\alpha-\mathrm{MSH}$ pulses were detected in any of the dogs. In one dog with dexamethasone-resistant

Figure 2 Box-plot graphs (median, interquartile and total range) for the basal plasma hormone concentration, the area under the curve (AUC), and the pulse frequency of $\mathrm{ACTH}$, cortisol, $\alpha-\mathrm{MSH}$ and $\mathrm{GH}$ in control dogs and in dogs with pituitary-dependent hyperadrenocorticism (PDH) before and 2-4 months after hypophysectomy (HX). Blood samples were collected at 10-min intervals for $6 \mathrm{~h}$. Outliers are indicated with circles; extreme values with triangles. For values that are off scale the actual value is given within brackets. Significant differences between groups are indicated with asterices above the boxplots. Asterices above the boxes for PDH dogs before $\mathrm{HX}$ indicate differences compared with the control dogs and asterices above the boxes for PDH dogs after HX indicate differences compared with $\mathrm{PDH}$ dogs before $\mathrm{HX} ;{ }^{*} P<0 \cdot 05 ;{ }^{+} P<0 \cdot 01 ;{ }^{\ddagger} P<0 \cdot 001$. 
Basal plasma concentration
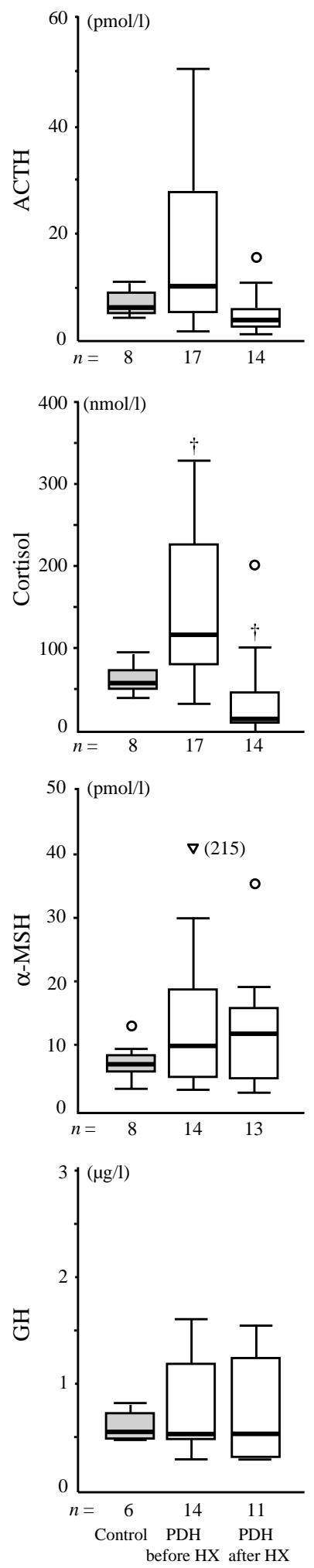

AUC

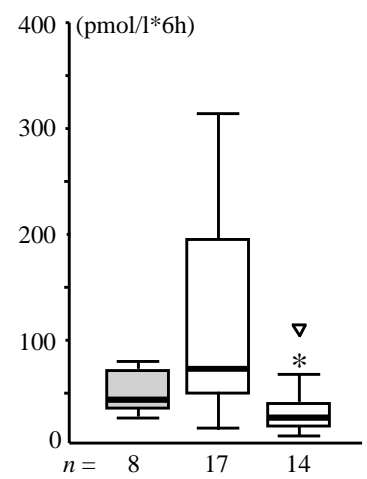

3000
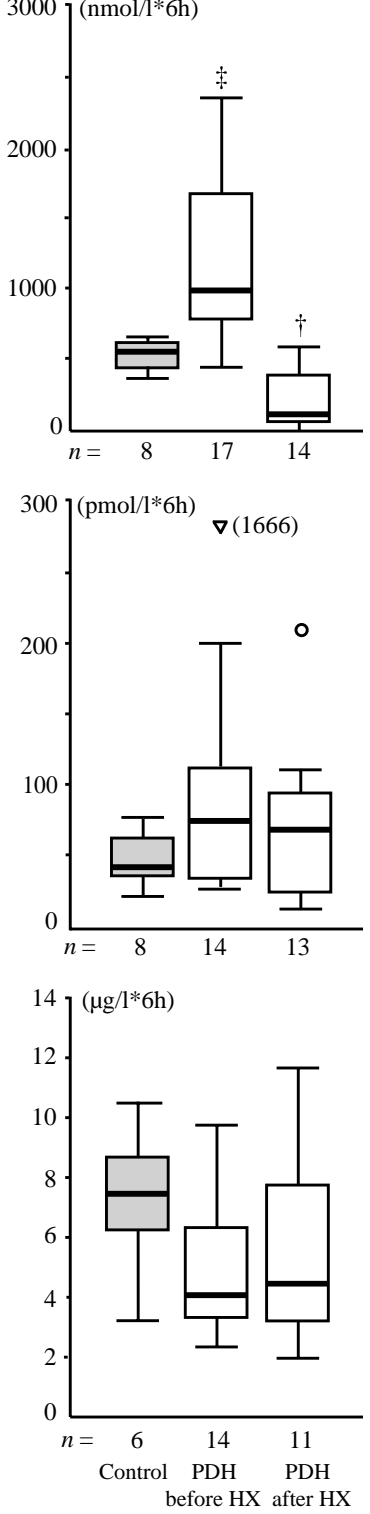

Pulse frequency
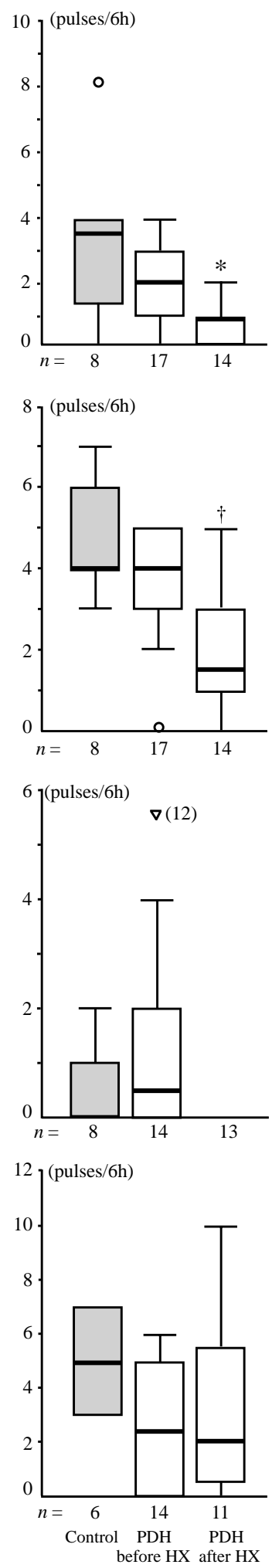
$\mathrm{PDH}$, a very high basal plasma $\alpha-\mathrm{MSH}$ concentration (215 pmol/1; reference range $\leq 36 \mathrm{pmol} / 1$ (Kooistra et al. 1997b, Bosje et al. 2002)) was found and 12 significant $\alpha-\mathrm{MSH}$ pulses identified (Fig. 1b). In this case, the postoperative basal $\alpha$-MSH concentration was $4 \cdot 5 \mathrm{pmol} / 1$ (Fig. $1 \mathrm{~b}$ ).

In the PDH dogs and in the controls $\alpha-\mathrm{MSH}$ pulses frequently coincided with ACTH pulses. In the controls, 3 out of 4 significant $\alpha$-MSH pulses coincided with significant ACTH pulses, whereas in the PDH cases, 9 out of 25 significant $\boldsymbol{\alpha}$-MSH pulses coincided with significant ACTH pulses. In the dog with 12 significant $\boldsymbol{\alpha}$-MSH pulses, only 3 (high) $\alpha$-MSH pulses coincided with a significant ACTH pulse (Fig. 1b). In some cases, an $\alpha-M S H$ pulse preceded an ACTH pulse.

\section{GH}

The basal plasma GH concentration, the AUC for GH, and the GH pulse frequency were not significantly different between controls and PDH dogs, and also not between the $\mathrm{PDH}$ cases before and after hypophysectomy. Significant GH pulses were detected in 11 out of 15 dogs with PDH. After hypophysectomy, significant $\mathrm{GH}$ pulses were detected in 8 out of the $11 \mathrm{PDH}$ cases.

\section{Disease-free period and identification of risk parameters}

The median disease-free period was 880 days (95\% CI, 732-1028 days). The 1 -year disease-free fraction was $87 \%$ (95\% CI, 56-96\%) and the 2-year disease-free fraction, 65\% (95\% CI, 35-84\%). In 9 out of the 16 cases, hyperadrenocorticism recurred after $1 \cdot 5-5 \cdot 5$ years. In the univariate Cox proportional hazard analysis, there was no association between preoperative hormone values and recurrence of hyperadrenocorticism. Of the values after hypophysectomy, the ACTH pulse frequency was associated with a significant $(P<0 \cdot 05)$ higher risk for recurrence of hyperadrenocorticism (hazard ratio 5·357; 95\% CI, 1·003-28·611). A higher AUC for $\mathrm{GH}$ after surgery tended to be associated with a lower risk of recurrence $(P=0 \cdot 076$; hazard ratio $0 \cdot 768,95 \%$ CI, 0.553-1·066).

\section{Discussion}

The results of this study demonstrate that the pulsatile nature of the pituitary hormone release is maintained in pituitarydependent hyperadrenocorticism. Significant pulses of ACTH (and consequently cortisol), $\alpha-\mathrm{MSH}$, and GH were identified in the plasma profiles of dogs with PDH. Interestingly, significant pulses were also observed in some of the cases in remission after hypophysectomy. The presence of significant ACTH pulses after surgery was identified as a risk factor for recurrence of hyperadrenocorticism.

Before surgery, the pulse frequencies of ACTH and cortisol in the PDH cases were not different from those in the controls, which is in agreement with previous reports on dogs (Orth et al. 1988) and on humans with Cushing's disease (van den Berg et al. 1995). In this study, the AUC for ACTH and ACTH pulse frequency decreased after hypophysectomy. In addition, the basal plasma cortisol concentration, the AUC for cortisol, and the cortisol pulse frequency decreased significantly and there was less co-occurrence between ACTH and cortisol pulses after surgery. In accordance with the relatively low values of the plasma profile characteristics for ACTH and cortisol after hypophysectomy, remission was achieved in all 16 dogs that survived the early postoperative period.

In this study, complete hypophysectomy with elimination of all ACTH-producing cells was the surgical goal. Hypophysectomy is consistent with a substantial reduction in the number of corticotropic cells, which leads to remission of hyperadrenocorticism. Nevertheless, there was residual ACTH secretion after hypophysectomy. Corticotropic cells are fairly resistant to elimination and complete removal of the pituitary gland is difficult to achieve (Ganong \& Hume 1956). Also, in what macroscopically appears to be an empty pituitary fossa, small remnant microscopic islets of pituitary cells capable of hormone production and response to $\mathrm{CRH}$ stimulation test have been found after hypophysectomy in both controls and PDH dogs (Niebauer et al. 1990, Meij et al. 1997a, 1997d, Axlund et al. 2005). The most likely origin of these cells are remnants from an incompletely removed pars distalis hypophysis (which easily falls apart upon manipulation) or, in the PDH cases, remnant adenomateous corticotropic cells. Less likely, the remnant cells may also originate from differentiated pituitary stem cells or from accessory pituitary tissue that, in the dog, is sporadically found in the dura mater lateral to the pituitary (von Nickel et al. 1992).

In previous reports, no remnant pituitary cells were identified on the ventral hypothalamic diencephalons in hypophysectomized experimental animals (Meij et al. 1997a, 1997d, Axlund et al. 2005). Therefore, it can be assumed that the pituitary-hypothalamic portal system is completely impeded and that the residual hormone secretion activity measured in this study originates from the microscopic islets in the pituitary fossa. Interestingly, the residual ACTH secretion was pulsatile in character. It is possible that this could be due to the influence of $\mathrm{CRH}$, to which the corticotropic cells in the pituitary residual islets are able to respond (Meij et al. 1997a, 1997d), reaching the pituitary cells on an alternative vascular route or through the cerebrospinal fluid from the opened third ventricle after hypophysectomy. The residual pulsatile ACTH secretion after hypophysectomy may also be explained by intrinsic ACTH pulsatility (Gambacciani et al. 1987), by release of vasopressin from the hypothalamus or by CRH-independent secretory capacity of corticotropic cells (Fukuda et al. 2004).

In agreement with earlier observations (Orth et al. 1988, Kooistra et al. 1997a), $\boldsymbol{\alpha}$-MSH was secreted in a pulsatile fashion in both the controls and the PDH dogs. Under basal conditions, the pars intermedia of the canine 
adenohypophysis is under strong and almost permanent dopaminergic inhibition (Peterson et al. 1986, Kemppainen \& Sartin 1988, Orth et al. 1988, Meij et al. 1997d). The significant $\boldsymbol{\alpha}$-MSH pulses are probably the result of a temporary decrease in the tonic hypothalamic dopaminergic inhibitory control. The administration of a dopamine antagonist such as haloperidol results in a significant release of $\alpha$-MSH (Orth et al. 1988, Kooistra et al. 1997a).

The $\alpha-\mathrm{MSH}$ pulsatility was similar in the PDH dogs and the controls. After hypophysectomy, there were no $\alpha-\mathrm{MSH}$ pulses. This is compatible with complete removal of the neurointermediate lobe. In a previous study on pituitary function after hypophysectomy in experimental animals, administration of the dopamine-antagonist haloperidol caused no elevation of the basal plasma $\alpha-\mathrm{MSH}$ concentration, whereas before surgery there was a 30 -fold increase (Meij et al. 1997d).

Several $\alpha-\mathrm{MSH}$ pulses co-occurred with ACTH pulses that is explained by co-release of ACTH and $\alpha-\mathrm{MSH}$ from the pars intermedia (Kooistra et al. 1997a) by the same secretagog or stimulatory event. Previous studies demonstrated that the dopamine-antagonist haloperidol increases the plasma concentrations of both $\alpha-\mathrm{MSH}$ and ACTH (Kemppainen \& Sartin 1988, Kooistra et al. 1997a). The haloperidolstimulated secretion of $\boldsymbol{\alpha}-\mathrm{MSH}$ reached its maximum value within $10 \mathrm{~min}$, whereas the haloperidol-stimulated secretion of ACTH reached its maximum value after $60 \mathrm{~min}$. Therefore, an $\alpha-\mathrm{MSH}$ pulse preceded an ACTH pulse in some cases of the present study.

Dogs with PDH and humans with Cushing's disease secrete less GH in pulses than healthy individuals (Veldman et al. 2000, Lee et al. 2003). The same was observed in the present study, although no statistical significance was reached. Sustained exposure to supraphysiological amounts of glucocorticoids inhibits pulsatile $\mathrm{GH}$ secretion and blunts the $\mathrm{GH}$ response to stimuli mainly by altering the hypothalamic somatostatin tone (Muller et al. 1999).

In the group of PDH dogs, hypophysectomy caused no further significant decrease in the already low plasma GH concentrations. However, in some individual cases, the decline of the basal GH values was distinct. These findings are in agreement with a previous study in which hypophysectomy led to a significant decrease in the plasma $\mathrm{GH}$ concentrations (Meij et al. 1997a). Plasma GH concentrations unaffected by hypophysectomy are most likely the result of secretion by residual somatotropic cells in the pituitary fossa (Hassan \& Merkel 1994, Meij et al. 1997a, 1997d). Another explanation is the extra-pituitary GH production that occurs in many tissues under both normal and pathologic conditions (Mol et al. 1995, van Garderen et al. 1997, Lantinga van Leeuwen et al. 2000, Harvey et al. 2001, 2004, Robben et al. 2002, Petterino et al. 2004). This extra-pituitary GH is mainly thought to have local autocrine and paracrine effects, but may also reach the systemic circulation. For example, progesterone-induced GH release from the mammary gland during the luteal phase may increase the plasma GH concentration in bitches (Kooistra \& Okkens 2002). However, hypophysectomy removes the FSH- and LHsecreting gonadotropic cells (resulting in permanent anoestrus and a very low plasma progesterone concentration), and therefore, it is unlikely that circulating GH after hypophysectomy is of mammary origin.

There was no association between preoperative characteristics of the plasma hormone profiles and recurrence of hyperadrenocorticism, which is in agreement with the results of a study after transsphenoidal hypophysectomy in humans with Cushing's disease (Buchfelder et al. 1993). The number of significant ACTH pulses after hypophysectomy, however, was identified as a risk for recurrence of hyperadrenocorticism. Consequently, pulsatile ACTH secretion at 8 weeks after hypophysectomy is more likely to reflect the presence of residual adenomatous than unaffected corticotropic cells in the pituitary fossa. In an earlier study, the $\mathrm{CRH}$-stimulation test 8 weeks after hypophysectomy effectively identified dogs with residual disease but failed to differentiate between the cases that developed recurrence of hyperadrenocorticism and those that remained in remission (Meij et al. 1997a). Thus, the intrinsic ability of pulsatile hormone release is more informative for the prognosis than the response to $\mathrm{CRH}$ stimulation at 8 weeks after hypophysectomy. The slow growth rate of the corticotropic adenoma may explain why hyperadrenocorticism recurs in $1 \cdot 5-5$ years. There was also a tendency that high postoperative AUC for $\mathrm{GH}$ was associated with a low risk of recurrence, which may be a reflection of normalized GH secretion of the residual somatotropic cells after successful elimination of inhibition by high cortisol levels.

In conclusion, the results of the present study indicate that in PDH dogs, ACTH, cortisol, $\alpha-\mathrm{MSH}$, and GH are secreted in a pulsatile fashion, and that hypophysectomy effectively reduces the secretion of ACTH and cortisol. The presence of ACTH pulses after hypophysectomy is associated with a higher risk of recurrence of hyperadrenocorticism.

\section{Acknowledgements}

We are grateful for the technical assistance of $\mathrm{Mr} \mathrm{H} \mathrm{G} \mathrm{H}$ van Engelen and Mrs J Wolfswinkel, and Dr G Voorhout for pituitary imaging and Dr W M Lee for data-typing. The critical reading of Prof. Dr A Rijnberk is highly appreciated. The authors declare that there is no conflict of interest that would prejudice the impartiality of this scientific work.

\section{References}

Axlund TW, Behrend EN, Sorjonen DC, Simpson ST \& Kemppainen RJ 2005 Canine hypophysectomy using a ventral paramedian approach. Veterinary Surgery 34 179-189.

Barker FG II, Klibanski A \& Swearingen B 2003 Transsphenoidal surgery for pituitary tumors in the United States, 1996-2000: mortality, morbidity, and the effects of hospital and surgeon volume. Journal of Clinical Endocrinology and Metabolism 88 4709-4719. 
van den Berg G, Frolich M, Veldhuis JD \& Roelfsema F 1995 Combined amplification of the pulsatile and basal modes of adrenocorticotropin and cortisol secretion in patients with Cushing's disease: evidence for decreased responsiveness of the adrenal glands. Journal of Clinical Endocrinology and Metabolism 80 3750-3757.

van den Berg G, Pincus SM, Veldhuis JD, Frolich M \& Roelfsema F 1997 Greater disorderliness of ACTH and cortisol release accompanies pituitarydependent Cushing's disease. European Journal of Endocrinology 136 394-400.

Bosje JT, Rijnberk A, Mol JA, Voorhout G \& Kooistra HS 2002 Plasma concentrations of ACTH precursors correlate with pituitary size and resistance to dexamethasone in dogs with pituitary-dependent hyperadrenocorticism. Domestic Animal Endocrinology 22 201-210.

Brabant G, Prank K \& Schöfl C 1992 Pulsatile patterns in hormone secretion. Trends in Endocrinology and Metabolism 3 183-190.

Buchfelder M, Fahlbusch R, Wentzlaff-Eggebert H, Brabant G, Stalla GK \& Muller OA 1993 Does an analysis of the pulsatile secretion pattern of adrenocorticotropin and cortisol predict the result of transsphenoidal surgery in Cushing's disease? Journal of Clinical Endocrinology and Metabolism $77720-724$

Corrada Y, Castex G, Sosa Y \& Gobello C 2003 Secretory patterns of prolactin in dogs: circannual and ultradian rhythms. Reproduction in Domestic Animals 38 219-223.

Eigenmann JE \& Eigenmann RY 1981 Radioimmunoassay of canine growth hormone. Acta Endocrinologica (Copenhagen) 98 514-520.

Fukuda Y, Kageyama K, Nigawara T, Kasagi Y \& Suda T 2004 Effects of corticotropin-releasing hormone $(\mathrm{CRH})$ on the synthesis and secretion of proopiomelanocortin-related peptides in the anterior pituitary: a study using CRH-deficient mice. Neuroscience Letters 367 201-204.

Galac S, Kooistra HS, Teske E \& Rijnberk A 1997 Urinary corticoid/creatinine ratios in the differentiation between pituitary-dependent hyperadrenocorticism and hyperadrenocorticism due to adrenocortical tumour in the dog. Veterinary Quarterly 19 17-20.

Gambacciani M, Liu JH, Swartz WH, Tueros VS, Rasmussen DD \& Yen SS 1987 Intrinsic pulsatility of ACTH release from the human pituitary in vitro. Clinical Endocrinology 26 557-563.

Ganong WF \& Hume DM 1956 The effect of graded hypophysectomy on thyroid, gonadal, and adrenocortical function in the dog. Endocrinology $\mathbf{5 9}$ 293-301.

van Garderen E, de Wit M, Voorhout WF, Rutteman GR, Mol JA, Nederbragt H \& Misdorp W 1997 Expression of growth hormone in canine mammary tissue and mammary tumors. Evidence for a potential autocrine/paracrine stimulatory loop. American Journal of Pathology 150 1037-1047.

Hanson JM, van 't Hoofd M, Voorhout G, Teske E, Kooistra HS \& Meij BP 2005 Efficacy of transsphenoidal hypophysectomy in treatment of dogs with pituitary-dependent hyperadrenocorticism. Journal of Veterinary Internal Medicine 19 687-694.

Harvey S, Johnson CD \& Sanders EJ 2001 Growth hormone in neural tissues of the chick embryo. Journal of Endocrinology 169 487-498.

Harvey S, Baudet ML, Murphy A, Luna M, Hull KL \& Aramburo C 2004 Testicular growth hormone (GH): GH expression in spermatogonia and primary spermatocytes. General and Comparative Endocrinology 139 158-167.

Hassan HA \& Merkel RA 1994 Perifusion model system to culture bovine hypothalamic slices in series with dispersed anterior pituitary cells. In Vitro Cellular and Developmental Biology - Animal 30A 435-442.

Kemppainen RJ \& Sartin JL 1984 Evidence for episodic but not circadian activity in plasma concentrations of adrenocorticotrophin, cortisol and thyroxine in dogs. Journal of Endocrinology 103 219-226.

Kemppainen RJ \& Sartin JL 1988 Differential secretion of pro-opiomelanocortin peptides by the pars distalis and pars intermedia of beagle dogs. Journal of Endocrinology 117 91-96.

Kemppainen RJ \& Peterson ME 1994 Animal models of Cushing's disease. Trends in Endocrinology and Metabolism 5 21-28.

Kooistra HS \& Okkens AC 2001 Secretion of prolactin and growth hormone in relation to ovarian activity in the dog. Reproduction in Domestic Animals 36 $115-119$.

Kooistra HS \& Okkens AC 2002 Secretion of growth hormone and prolactin during progression of the luteal phase in healthy dogs: a review. Molecular and Cellular Endocrinology 197 167-172.
Kooistra HS, Greven SH, Mol JA \& Rijnberk A 1997a Pulsatile secretion of alpha-MSH and the differential effects of dexamethasone and haloperidol on the secretion of alpha-MSH and ACTH in dogs. Journal of Endocrinology 152 113-121.

Kooistra HS, Voorhout G, Mol JA \& Rijnberk A $1997 b$ Correlation between impairment of glucocorticoid feedback and the size of the pituitary gland in dogs with pituitary-dependent hyperadrenocorticism. Journal of Endocrinology 152 387-394.

Kooistra HS, Okkens AC, Bevers MM, Popp-Snijders C, van Haaften B, Dieleman SJ \& Schoemaker J 1999 Concurrent pulsatile secretion of luteinizing hormone and follicle-stimulating hormone during different phases of the estrous cycle and anestrus in beagle bitches. Biology of Reproduction 60 65-71.

Lamberts SW 2002 Glucocorticoid receptors and Cushing's disease. Molecular and Cellular Endocrinology 197 69-72.

Lantinga van Leeuwen IS, Teske E, van Garderen E \& Mol JA 2000 Growth hormone gene expression in normal lymph nodes and lymphomas of the dog. Anticancer Research 20 2371-2376.

Lee WM, Meij BP, Bhatti SF, Mol JA, Rijnberk A \& Kooistra HS 2003 Pulsatile secretion pattern of growth hormone in dogs with pituitarydependent hyperadrenocorticism. Domestic Animal Endocrinology 24 59-68.

Meij BP, Mol JA, Bevers MM \& Rijnberk A 1997a Residual pituitary function after transsphenoidal hypophysectomy in dogs with pituitarydependent hyperadrenocorticism. Journal of Endocrinology 155 531-539.

Meij BP, Mol JA, Bevers MM \& Rijnberk A $1997 b$ Alterations in anterior pituitary function of dogs with pituitary-dependent hyperadrenocorticism. Journal of Endocrinology 154 505-512.

Meij BP, Voorhout G, van den Ingh TSGAM, Hazewinkel HA \& Van't Verlaat JW 1997c Transsphenoidal hypophysectomy in beagle dogs: evaluation of a microsurgical technique. Veterinary Surgery 26 295-309.

Meij BP, Mol JA, van den Ingh TSGAM, Bevers MM, Hazewinkel HA \& Rijnberk A 1997d Assessment of pituitary function after transsphenoidal hypophysectomy in beagle dogs. Domestic Animal Endocrinology 14 81-97.

Meij BP, Voorhout G, van den Ingh TSGAM, Hazewinkel HA, Teske E \& Rijnberk A 1998 Results of transsphenoidal hypophysectomy in 52 dogs with pituitary-dependent hyperadrenocorticism. Veterinary Surgery 27 246-261.

Merriam GR \& Wachter KW 1982 Algorithms for the study of episodic hormone secretion. American Journal of Physiology 243 E310-E318.

Mol JA, van Garderen E, Selman PJ, Wolfswinkel J, Rijinberk A \& Rutteman GR 1995 Growth hormone mRNA in mammary gland tumors of dogs and cats. Journal of Clinical Investigations 95 2028-2034.

Muller EE, Locatelli V \& Cocchi D 1999 Neuroendocrine control of growth hormone secretion. Physiological Reviews 79 511-607.

von Nickel R, Schummer A \& Seiferle E 1992 Hirnanhang, hypophysis, glandula pituitaria. In Lehrbuch der Anatomie der Haustiere. Bd 4.

Nervensystem, Sinnesorgane, Endokrine Drüsen, 3 edn, pp 477-482. Ed G van Böhme. Berlin and Hamburg: Verlag Paul Parey.

Niebauer GW, Eigenmann JE \& Van Winkle TJ 1990 Study of long-term survival after transsphenoidal hypophysectomy in clinically normal dogs. American Journal of Veterinary Research 51 677-681.

Orth DN, Peterson ME \& Drucker WD 1988 Plasma immunoreactive proopiomelanocortin peptides and cortisol in normal dogs and dogs with Cushing's syndrome: diurnal rhythm and responses to various stimuli. Endocrinology 122 1250-1262.

Pereira AM, van Aken MO, van Dulken H, Schutte PJ, Biermasz NR, Smit JW, Roelfsema F \& Romijn JA 2003 Long-term predictive value of postsurgical cortisol concentrations for cure and risk of recurrence in Cushing's disease. Journal of Clinical Endocrinology and Metabolism 88 5858-5864.

Peterson ME, Orth DN, Halmi NS, Zielinski AC, Davis DR, Chavez FT \& Drucker WD 1986 Plasma immunoreactive proopiomelanocortin peptides and cortisol in normal dogs and dogs with Addison's disease and Cushing's syndrome: basal concentrations. Endocrinology 119 720-730.

Petterino C, Martini M \& Castagnaro M 2004 Immunohistochemical detection of growth hormone $(\mathrm{GH})$ in canine hepatoid gland tumors. Journal of Veterinary Medical Science 66 569-572.

Raff H \& Findling JW 1989 A new immunoradiometric assay for corticotropin evaluated in normal subjects and patients with Cushing's syndrome. Clinical Chemistry 35 596-600. 
Rees DA, Hanna FW, Davies JS, Mills RG, Vafidis J \& Scanlon MF 2002 Long-term follow-up results of transsphenoidal surgery for Cushing's disease in a single centre using strict criteria for remission. Clinical Endocrinology (Oxford) 56 541-551.

Reimondo G, Paccotti P, Minetto M, Termine A, Stura G, Bergui M, Angeli A \& Terzolo M 2003 The corticotrophin-releasing hormone test is the most reliable noninvasive method to differentiate pituitary from ectopic ACTH secretion in Cushing's syndrome. Clinical Endocrinology (Oxford) 58 718-724.

Rijnberk A, Mol JA, Rothuizen J, Bevers MM \& Middleton DJ 1987 Circulating pro-opiomelanocortin-derived peptides in dogs with pituitarydependent hyperadrenocorticism. Frontiers of Hormone Research 17 48-60.

Rijnberk A, van Wees A \& Mol JA 1988a Assessment of two tests for the diagnosis of canine hyperadrenocorticism. Veterinary Record 122 178-180.

Rijnberk A, Mol JA, Kwant MM \& Croughs RJM $1988 b$ Effects of bromocriptine on corticotrophin, melanotrophin and corticosteroid secretion in dogs with pituitary-dependent hyperadrenocorticism. Journal of Endocrinology 118 271-277.

Robben JH, Van Garderen E, Mol JA, Wolfswinkel J \& Rijnberk A 2002 Locally produced growth hormone in canine insulinomas. Molecular and Cellular Endocrinology 197 187-195.

Roelfsema F, Pincus SM \& Veldhuis JD 1998 Patients with Cushing's disease secrete adrenocorticotropin and cortisol jointly more asynchronously than healthy subjects. Journal of Clinical Endocrinology and Metabolism 83 688-692.
Stolp R, Rijnberk A, Meijer JC \& Croughs RJM 1983 Urinary corticoids in the diagnosis of canine hyperadrenocorticism. Research in Veterinary Science 34 141-144.

van der Vlugt-Meijer RH, Voorhout G \& Meij BP 2002 Imaging of the pituitary gland in dogs with pituitary-dependent hyperadrenocorticism. Molecular and Cellular Endocrinology 197 81-87.

van der Vlugt-Meijer RH, Meij BP, van den Ingh TSGAM, Rijnberk A \& Voorhout G 2003 Dynamic computed tomography of the pituitary gland in dogs with pituitary-dependent hyperadrenocorticism. Journal of Veterinary Internal Medicine 17 773-780.

van Vonderen IK, Kooistra HS \& Rijnberk A 1997 Intra- and interindividual variation in urine osmolality and urine specific gravity in healthy pet dogs of various ages. Journal of Veterinary Internal Medicine 11 30-35.

Veldman RG, Frolich M, Pincus SM, Veldhuis JD \& Roelfsema F 2000 Growth hormone and prolactin are secreted more irregularly in patients with Cushing's disease. Clinical Endocrinology 52 625-632.

\section{Received 1 February 2006 \\ Received in final form 29 May 2006 \\ Accepted 6 June 2006}

